\title{
Investigation on Mercury Reemission from Limestone-Gypsum Wet Flue Gas Desulfurization Slurry
}

\author{
Chuanmin Chen, Songtao Liu, Yang Gao, and Yongchao Liu \\ School of Environmental Science \& Engineering, North China Electric Power University, Baoding 071003, China \\ Correspondence should be addressed to Chuanmin Chen; chuanminchen@gmail.com
}

Received 31 August 2013; Accepted 15 January 2014; Published 4 March 2014

Academic Editors: J. Canario, G.-C. Fang, and F. Scala

Copyright ( 2014 Chuanmin Chen et al. This is an open access article distributed under the Creative Commons Attribution License, which permits unrestricted use, distribution, and reproduction in any medium, provided the original work is properly cited.

Secondary atmospheric pollutions may result from wet flue gas desulfurization (WFGD) systems caused by the reduction of $\mathrm{Hg}^{2+}$ to $\mathrm{Hg}^{0}$ and lead to a damping of the cobenefit mercury removal efficiency by WFGD systems. The experiment on $\mathrm{Hg}^{0}$ reemission from limestone-gypsum WFGD slurry was carried out by changing the operating conditions such as the $\mathrm{pH}$, temperature, $\mathrm{Cl}^{-}$ concentrations, and oxygen concentrations. The partitioning behavior of mercury in the solid and liquid byproducts was also discussed. The experimental results indicated that the $\mathrm{Hg}^{0}$ reemission rate from WFGD slurry increased as the operational temperatures and $\mathrm{pH}$ values increased. The $\mathrm{Hg}^{0}$ reemission rates decreased as the $\mathrm{O}_{2}$ concentration of flue gas and $\mathrm{Cl}^{-}$concentration of WFGD slurry increased. The concentrations of $\mathrm{O}_{2}$ in flue gas have an evident effect on the mercury retention in the solid byproducts. The temperature and $\mathrm{Cl}^{-}$concentration have a slight effect on the mercury partitioning in the byproducts. No evident relation was found between mercury retention in the solid byproducts and the $\mathrm{pH}$. The present findings could be valuable for industrial application of characterizing and optimizing mercury control in wet FGD systems.

\section{Introduction}

Mercury and its compounds are highly toxic species which have a considerable impact on human health. A large proportion of mercury is emitted to the environment by the burning of coal. This process is responsible for about onethird of anthropogenic mercury emissions $[1,2]$. Mercury may be present in flue gas as elemental mercury $\left(\mathrm{Hg}^{0}\right)$ or oxidized mercury $\left(\mathrm{Hg}^{2+}\right)$. It may also be retained in fly ash particles, in which case it is referred to as particle-bound mercury $\left(\mathrm{Hg}^{\mathrm{P}}\right)$. Whereas $\mathrm{Hg}^{\mathrm{P}}$ is retained in the electrostatic precipitators or bag filters, both $\mathrm{Hg}^{2+}$ and $\mathrm{Hg}^{0}$ species from the flue gas are emitted to the atmosphere in power plants without undergoing any postcombustion processes to reduce emissions. In some cases, wet flue gas desulfurization (WFGD) systems installed in coal fired power plants to control $\mathrm{SO}_{2}$ emissions have been used to decrease mercury emissions [3-7]. In such systems, $\mathrm{SO}_{2}$ usually reacts with the limestone slurry to produce insoluble gypsum.

$\mathrm{Hg}^{2+}$ can be efficiently captured in WFGD by taking advantage of its high solubility in water $[3,5,8]$. However, the elemental mercury is difficult to capture with typical air pollution control devices (APCD) due to its volatility and chemical stability [1]. One strategy which is being explored is the use of a catalyst or oxidant to oxidize elemental mercury in the upstream of WFGD system, and then the oxidized mercury is absorbed by WFGD slurry. However, during the work aimed at enhancing the mercury-removal performance of WFGD systems, investigators discovered that a portion of absorbed oxidized mercury will be reduced to elemental mercury $\left(\mathrm{Hg}^{0}\right)$ in WFGD system and eventually released into flue gas [9-11], and the total mercury removal efficiency was significantly limited. As such, to improve the efficiency, it is necessary to control mercury reemission from WFGD slurry to prevent from reducing the cobenefit of wet scrubber mercury removal.

Studies on elemental mercury reemission in lab- and pilot-scale WFGD systems were reported in recent years. Some researchers indicated that the reduction process presumably occurred via aqueous reduction of $\mathrm{Hg}^{2+}$ by sulfite ions. The process was initiated by the formation of unstable intermediate, $\mathrm{HgSO}_{3}$, which immediately decomposed to 
aqueous $\mathrm{Hg}^{0}$ and eventually reemitted to gas phase [1113]. The authors also studied the effect of some operational parameters, for example, $\mathrm{pH}$ value, concentration of S(IV), temperature, and concentration of $\mathrm{Cl}^{-}$on elemental mercury reemission [10, 14, 15]. Wo et al. [10] indicated that flue gas $\mathrm{Hg}^{0}$ reemission across a wet FGD scrubber can be reduced by increasing the initial $\mathrm{pH}$ value, concentration of S(IV), or lowering the temperature. But $\mathrm{Wu}$ et al. [15] had the opposite conclusion about the effect of $\mathrm{pH}$ on the mercury reemission. Their work suggested that $\mathrm{Hg}^{0}$ reemission was suppressed by decreasing the $\mathrm{pH}$. They also suggested that there existed a qualitative relationship between the initial oxidation-reduction potential (ORP) values of the slurries and $\mathrm{Hg}^{0}$ reemission across the slurries [15]. Some literatures $[10,12]$ had yet concluded that the $\mathrm{Cl}^{-}$had inhibition effect on the reduction of $\mathrm{Hg}^{2+}$, where the formation of $\mathrm{ClHgSO}_{3}{ }^{-}$ was suggested as the main cause for this inhibition [16].

Furthermore, these parameters not only affect $\mathrm{Hg}^{0}$ reemission, but also impact the partitioning behavior of mercury in the solid and liquid byproducts. To better understand the performance of $\mathrm{Hg}^{0}$ reemission in the wet FGD system, a sequence of experiments was carried out in order to evaluate the influence of different operational parameters on $\mathrm{Hg}^{0}$ reemission efficiency in a bubbling reactor and the partitioning behavior of mercury in the solid and liquid byproducts was also discussed.

\section{Experiments and Methods}

2.1. Experimental Apparatus. The schematic diagram of a labscale wet FGD simulated system is illustrated in Figure 1. The elemental mercury $\left(\mathrm{Hg}^{0}\right)$ reemission and the factors that impact $\mathrm{Hg}^{0}$ reemission were investigated by using the simulated scrubber. This system consisted of an oxidized mercury $\left(\mathrm{Hg}^{2+}\right)$ injection system, carrier gas system, scrubbing system, and mercury analyzer system. The scrubbing system was composed of a bubbling reactor, a water bath, and a magnetic stirring system. The $\mathrm{Hg}^{2+}$ injection system was a peristaltic pump system, which can deliver the $\mathrm{HgCl}_{2}$ solution to the bubbling reactor as the source as well as control and adjust its injection rates. The $\mathrm{Hg}^{2+}$ solution went directly to the bottom of the flask through a Teflon tube. The carrier gas system included cylinder gases, mass flow controllers (MFCs), and delivery piping, which was made of Teflon tubes. The desired flow rates of the carrier gases were controlled by calibrated MFCs. The reaction solution was stirred under $\mathrm{N}_{2}, \mathrm{O}_{2}$, and $\mathrm{CO}_{2}$ atmosphere to remove the produced $\mathrm{Hg}^{0}$.

2.2. Experimental Procedure. At the beginning of each test, a slurry with the desired concentration $(1 \% \mathrm{w} / \mathrm{w})$ was prepared and poured into the reactor; the reactor was submerged into the water bath at the desired temperature. The $\mathrm{CaSO}_{4}$ and $\mathrm{CaSO}_{3}$ (mixing rate, 90/10) were used to simulate the slurry of the limestone-forced oxidation wet FGD system. The $\mathrm{Hg}^{2+}$ injection system was a peristaltic pump system, which can deliver the $\mathrm{HgCl}_{2}$ solution to the bubbling reactor as the

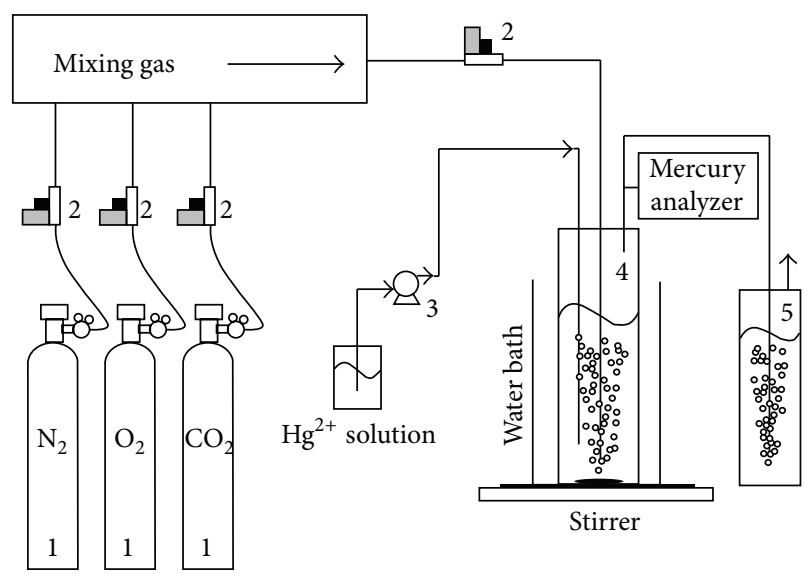
(1) Cylinder
(4) Bubbling reactor
(2) Mass flow controllers
(5) Tail gas treatment
(3) Peristaltic pump

FIGURE 1: Schematic of the experiment system.

source of $\mathrm{Hg}^{2+}$ as well as control and adjust its injection rates. A $50 \mu \mathrm{g} / \mathrm{l} \mathrm{Hg}^{2+}$ solution was pumped into the reactor at a rate of $10 \mathrm{~mL} / \mathrm{h}$. The initial $\mathrm{pH}$ of the solution was controlled through the combined addition of $\mathrm{CaCO}_{3}$ and $\mathrm{H}_{2} \mathrm{SO}_{4}$ to the reactor and measured by $\mathrm{pH}$ meter. Other chemicals, such as $\mathrm{NaCl}$ as the source of $\mathrm{Cl}^{-}$, were selectively added to the bubbling reactor. The carrier gas with a flow rate of $1000 \mathrm{~mL} / \mathrm{min}$ was introduced into the scrubber. The carrier gas came in contact with the slurry through the scrubber. Then, the carrier gas arrived at the mercury analyzer, which initiated the test. When the blank testing values of the mercury concentrations in the carrier gas were stable, the $\mathrm{Hg}^{2+}$ solution was injected. Continuous $\mathrm{Hg}^{0}$ concentration detection at the outlet of the simulated WFGD reactor was started at this point by a LUMEX RA-915+ Hg analyzer until the steady state was achieved. The mercury content of the solid and aqueous samples generated in the lab-scale tests was also determined by means of LUMEX RA-915+ $\mathrm{Hg}$ analyzer. No oxidized mercury was detected through multiple tests because the oxidized mercury dissolved in the slurry. The elemental mercury concentration that was emitted from the slurry was tested to quantify the elemental mercury reemission levels. The mercury concentrations were recorded once per minute. The mercury mass balance for each test was calculated. It is found that the error of the overall mercury mass balance was in the range of $94 \%-105 \%$ for all tests. The range of experimental conditions used for the scrubber slurry and the simulated flue gas is included in Table 1.

2.3. Mercury Reemission Efficiency Calculation. In this paper, mercury reemission efficiency $\left(\eta_{\mathrm{Hg}^{0}}\right)$ was calculated by the equation listed as follows:

$$
\eta_{\mathrm{Hg}^{0}}=\frac{c_{\mathrm{Hg}_{\mathrm{out}}^{0}}}{c_{\mathrm{Hg}_{\mathrm{in}}^{2+}}^{2+}} \times 100 \%
$$


TABLE 1: Experimental conditions.

\begin{tabular}{lcc}
\hline Parameter & Simulated WFGD slurry & Simulated flue gas \\
\hline Reagent & $90 \% \mathrm{CaSO}_{4} / 10 \% \mathrm{CaSO}_{3}$ & - \\
Initial $\mathrm{pH}$ & $3-7$ & - \\
Temperature $\left({ }^{\circ} \mathrm{C}\right)$ & $20-75$ & 20 \\
$\mathrm{O}_{2}($ vol. $\%)$ & - & $0-15$ \\
$\mathrm{CO}_{2}($ vol. $\%)$ & - & 12 \\
$\mathrm{~N}_{2}($ vol.\%) & - & As balance \\
$\mathrm{Gas}_{\text {flow rate }(\mathrm{mL} / \mathrm{min})}$ & 50 & 1000 \\
$\mathrm{Hg}^{2+}$ concentration $(\mu \mathrm{g} / \mathrm{L})$ & 10 & - \\
$\mathrm{Hg}^{2+}$ injection rate $(\mathrm{mL} / \mathrm{h})$ & - & - \\
$\mathrm{Hg}^{2+}$ concentration at scrubbing system inlet (calculated in gas, $\mu \mathrm{g} / \mathrm{m}^{3}$ gas $)$ & $0-5000$ & 8.3 \\
$\mathrm{Cl}^{-}(\mathrm{ppm})$ & & - \\
\hline
\end{tabular}

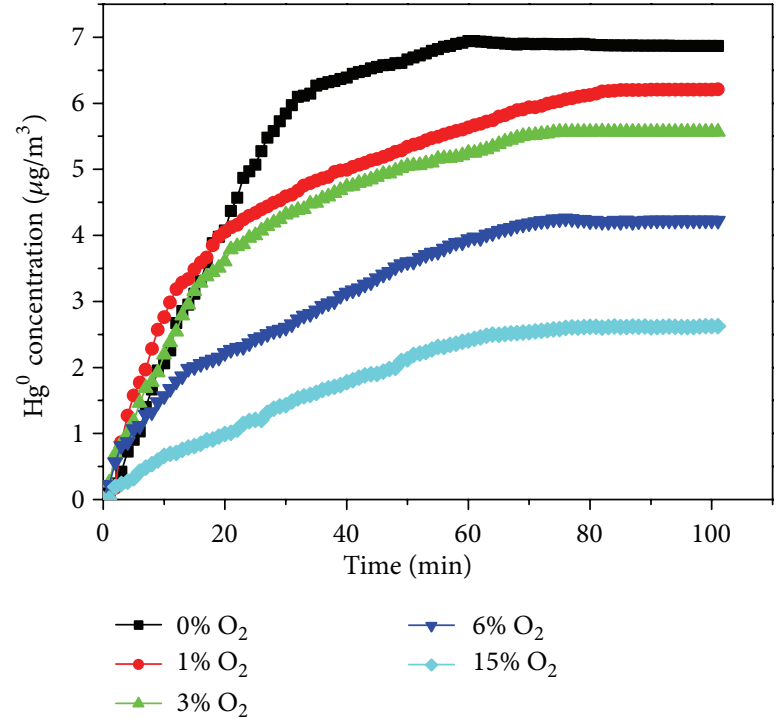

(a)

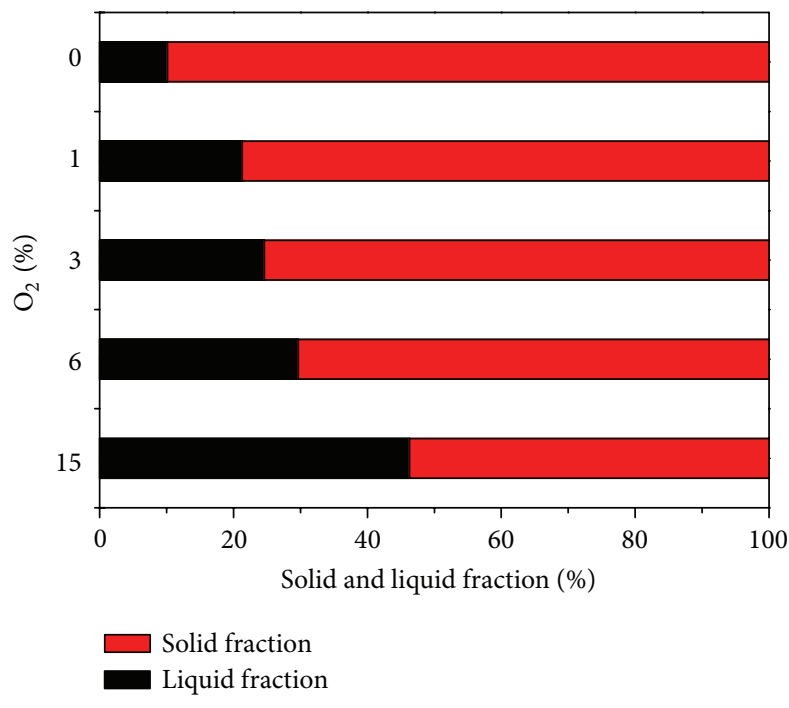

(b)

FiguRE 2: (a) Effect of the oxygen concentration in the flue gas on $\mathrm{Hg}^{0}$ reemission. (b) Relationship between the proportion of mercury retained in the solid and liquid fraction of the slurry and the concentration of oxygen concentration in the flue gas.

where $\eta_{\mathrm{Hg}^{0}}$ is the mercury reemission efficiency, $c_{\mathrm{Hg}_{\mathrm{in}}^{2+}}$ is the inlet $\mathrm{Hg}^{2+}$ concentrations, and $c_{\mathrm{Hg}_{\text {out }}^{0}}$ is the outlet $\mathrm{Hg}^{0}$ concentration.

\section{Results and Discussion}

3.1. Effect of the Oxygen Concentration in the Flue Gas on $\mathrm{Hg}^{0}$ Reemission. The impact of oxygen concentration in the flue gas on $\mathrm{Hg}^{0}$ reemission from the simulated WFGD slurry is shown in Figure 2. The experiments reported in Figure 2 were performed at a $\mathrm{pH}$ of 5.5 and a temperature of $55^{\circ} \mathrm{C}$. The experimental range of oxygen concentration used in these experiments was from $0 \%$ to $15 \%$. From Figure 2(a), it can be seen that the $\mathrm{Hg}^{0}$ reemission rates increase as the oxygen concentration in the flue gas increases. The $\mathrm{Hg}^{0}$ concentration in flue gas reached about $6.87 \mu \mathrm{g} / \mathrm{m}^{3}$ for $0 \% \mathrm{O}_{2}$ at $100 \mathrm{~min}$ when $\mathrm{Hg}^{0}$ concentration was stable. In contrast, only $2.62 \mu \mathrm{g} / \mathrm{m}^{3}$ was obtained for $15 \% \mathrm{O}_{2}$. The $\mathrm{Hg}^{0}$ reemission reaction mechanism is explained by using the chemical reaction in [15]

$$
\mathrm{Hg}^{2+}+\mathrm{HSO}_{3}{ }^{-}+\mathrm{H}_{2} \mathrm{O} \longleftrightarrow \mathrm{Hg}^{0}+\mathrm{SO}_{4}{ }^{2-}+3 \mathrm{H}^{+}
$$

The $\mathrm{SO}_{3}{ }^{2-}$ was oxidized into $\mathrm{SO}_{4}{ }^{2-}$ through reaction (3) when the carrier gas that contained $\mathrm{O}_{2}$ was blown into the scrubber. Thus, the concentration of $\mathrm{HSO}_{3}{ }^{-}$was decreased, which resulted in a lower $\mathrm{Hg}^{0}$ reemission rate:

$$
2 \mathrm{SO}_{3}{ }^{2-}+\mathrm{O}_{2} \longrightarrow 2 \mathrm{SO}_{4}{ }^{2-}
$$

The mercury partitioning in the byproducts indicates that an increase in mercury retention in the solid fraction occurs at lower concentrations of $\mathrm{O}_{2}$ in flue gas (Figure 2(b)). This suggests that sulfate ions may be contributing to the formation of a small amount of mercury sulfate which then precipitates with the gypsum particles or decomposes in $\mathrm{HgO}(\mathrm{s})[14]$. 


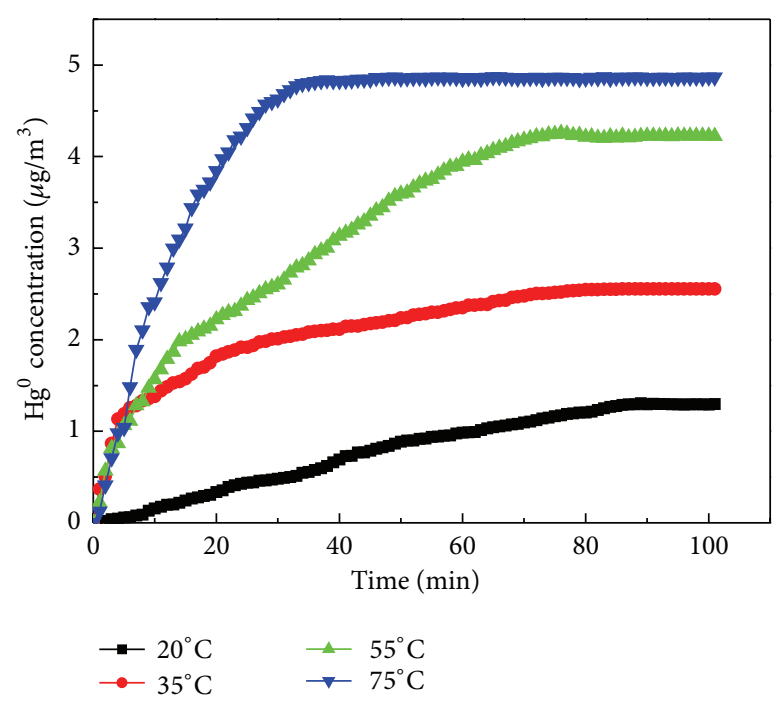

(a)

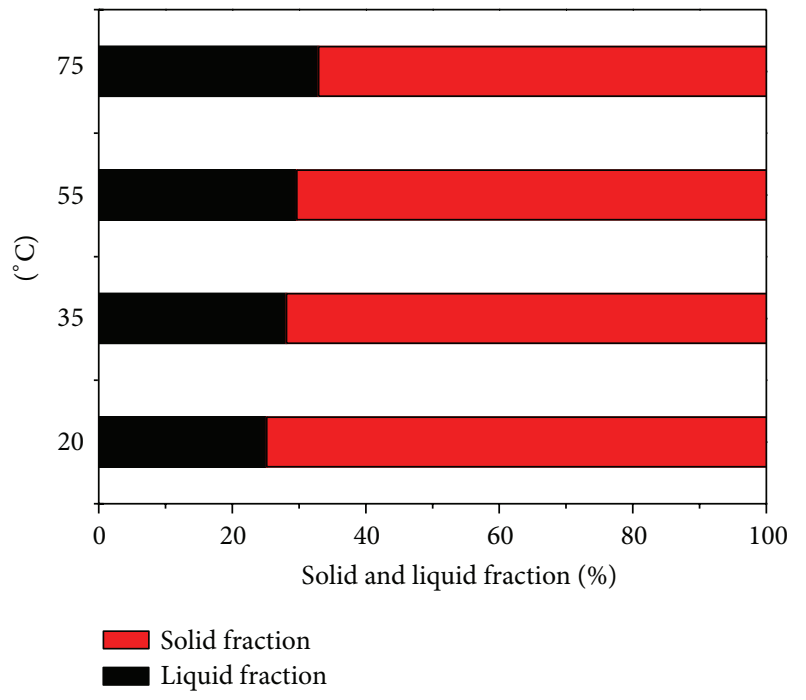

(b)

FIGURE 3: (a) Effect of the temperature on $\mathrm{Hg}^{0}$ reemission. (b) Relationship between the proportion of mercury retained in the solid and liquid fraction of the slurry and the temperature.

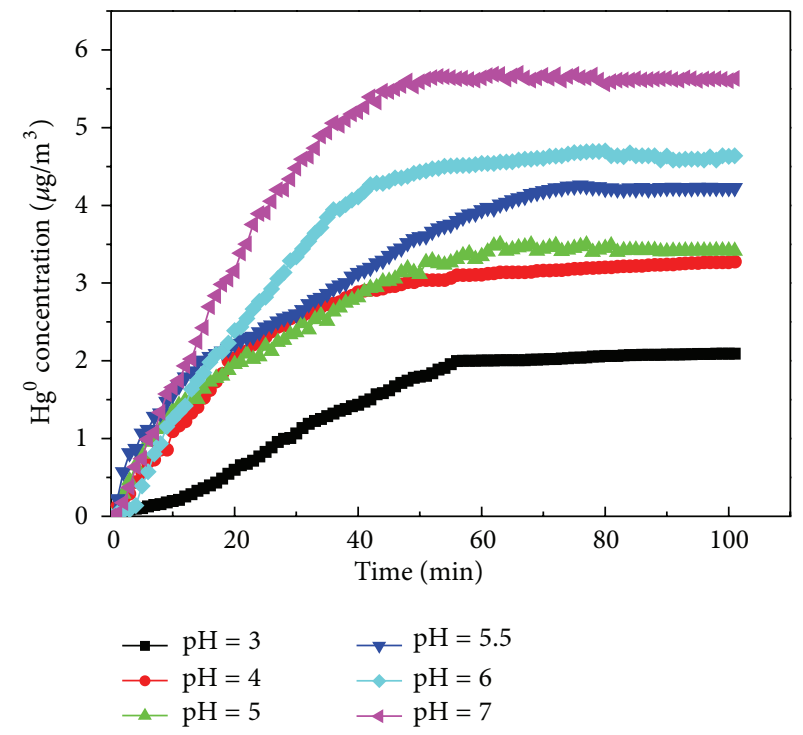

(a)

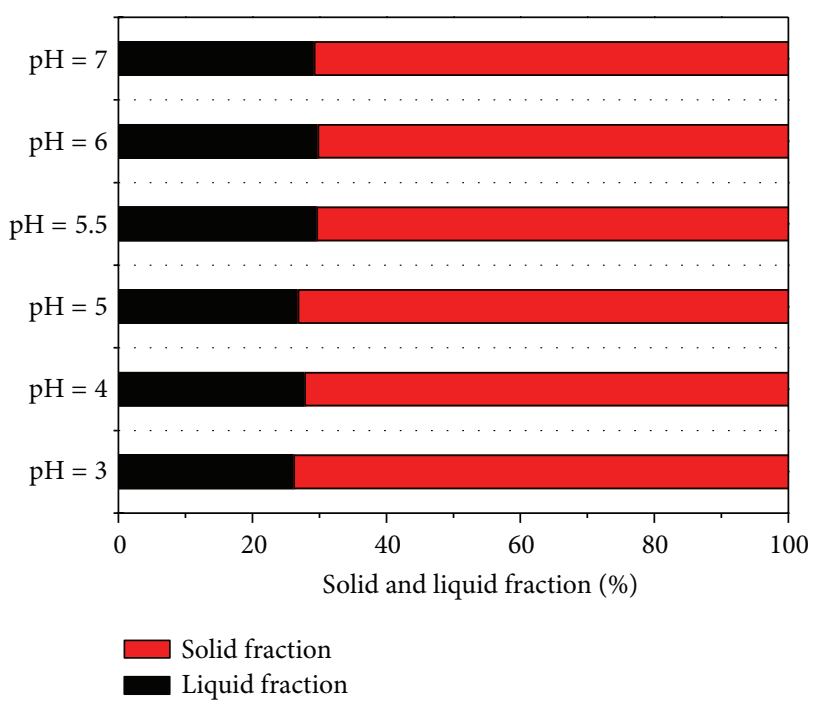

(b)

Figure 4: (a) Effect of the $\mathrm{pH}$ on $\mathrm{Hg}^{0}$ reemission. (b) Relationship between the proportion of mercury retained in the solid and liquid fraction of the slurry and the $\mathrm{pH}$.

3.2. Effect of the Temperature on $\mathrm{Hg}^{0}$ Reemission. The tests of $\mathrm{Hg}^{0}$ reemission at different temperatures were conducted. The experimental range of temperature used in these experiments was from 20 to $75^{\circ} \mathrm{C}$ by adjusting the temperature of the water bath. The $\mathrm{pH}$ value of the slurry was kept at 5.5. Figure 3(a) shows the elemental mercury concentrations versus the $\mathrm{HgCl}_{2}$ injection time at four temperature levels. It can be seen that the $\mathrm{Hg}^{0}$ reemission rate increases with the temperature of the simulated scrubber. $\mathrm{The}^{\mathrm{H}}{ }^{0}$ concentration in flue gas reached about $4.87 \mu \mathrm{g} / \mathrm{m}^{3}$ at $75^{\circ} \mathrm{C}$ at an injection time of $100 \mathrm{~min}$, while it was only $1.29 \mu \mathrm{g} / \mathrm{m}^{3}$ at $20^{\circ} \mathrm{C}$. Figure $3(\mathrm{~b})$ shows that there was a slight decrease in mercury retention in the solid fraction with the temperature rising.

3.3. Effect of the $\mathrm{pH}$ on $\mathrm{Hg}^{0}$ Reemission. Six tests at different initial $\mathrm{pH}$ values $(3,4,5,5.5,6$, and 7$)$ were conducted in the simulated scrubber. The temperature of the solution was $55^{\circ} \mathrm{C}$. The $\mathrm{Hg}^{0}$ concentration curves at different $\mathrm{pH}$ values are shown in Figure 4. From Figure 4(a), it can be found that the $\mathrm{Hg}^{0}$ reemission rates increase as the $\mathrm{pH}$ values increase. The $\mathrm{Hg}^{0}$ concentration in flue gas reached about $5.60 \mu \mathrm{g} / \mathrm{m}^{3}$ for $\mathrm{pH}=7$ at $100 \mathrm{~min}$. In contrast, only $2.09 \mu \mathrm{g} / \mathrm{m}^{3}$ was obtained for $\mathrm{pH}=3$. Equation (2) was a reversible reaction, according 


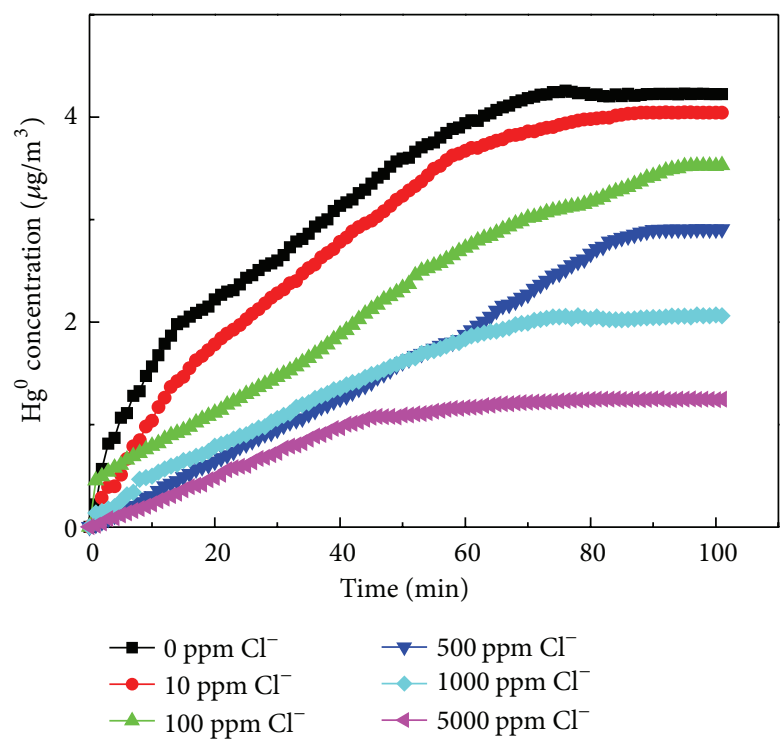

(a)

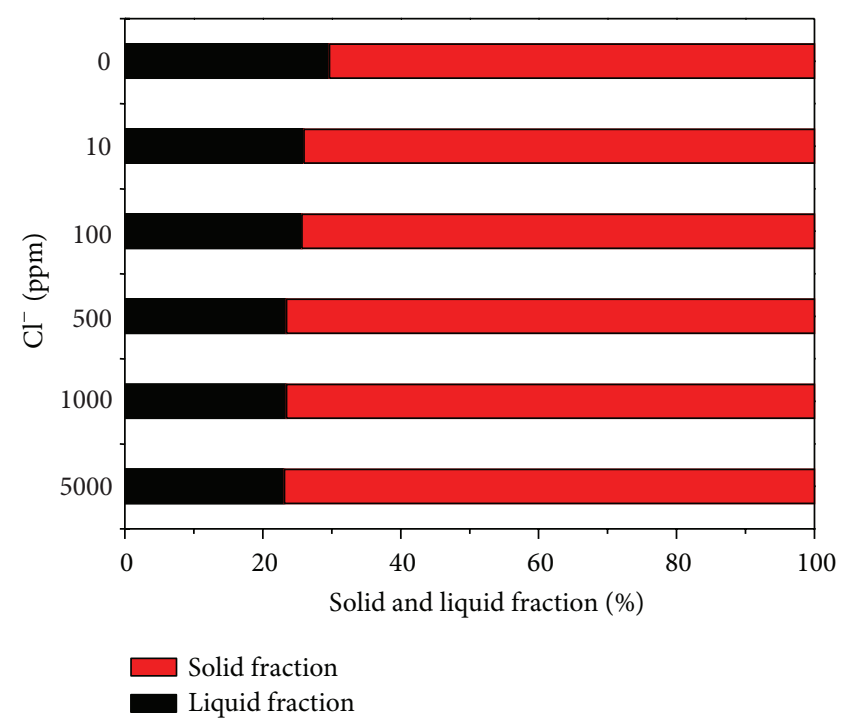

(b)

Figure 5: (a) Effect of the $\mathrm{Cl}^{-}$concentration on $\mathrm{Hg}^{0}$ reemission. (b) Relationship between the proportion of mercury retained in the solid and liquid fraction of the slurry and the $\mathrm{Cl}^{-}$.

to the principle of chemical reactions, and a counter reaction was performed at a lower $\mathrm{pH}$ value, where the concentration of $\mathrm{H}^{+}$was high. Therefore, the $\mathrm{Hg}^{0}$ reemission rate decreased in the solution as the $\mathrm{pH}$ value decreased. From Figure 4(a), it can be seen that the $\mathrm{pH}$ seems to have no effect on the mercury partitioning in the byproducts.

3.4. Effect of the $\mathrm{Cl}^{-}$Concentration on $\mathrm{Hg}^{0}$ Reemission. Figure 5 presents the effect of $\mathrm{Cl}^{-}$concentration on $\mathrm{Hg}^{0}$ reemission. The experiments were carried out at the $\mathrm{pH}$ value of 5.5 and the temperature of $55^{\circ} \mathrm{C}$. It can be seen that $\mathrm{Cl}^{-}$ concentration has an evident effect on the $\mathrm{Hg}^{0}$ reemission. The $\mathrm{Hg}^{0}$ reemission shows that the fastest reaction rate in the simulated desulfurization slurry is without chloride and the $\mathrm{Hg}^{0}$ reemission rate decreases with $\mathrm{Cl}^{-}$increasing. From Figure 5 it can be seen that the $\mathrm{Hg}^{0}$ concentration in flue gas reached about $4.23 \mu \mathrm{g} / \mathrm{m}^{3}$ without $\mathrm{Cl}^{-}$at $100 \mathrm{~min}$ while only $1.24 \mu \mathrm{g} / \mathrm{m}^{3}$ with $5000 \mathrm{ppm} \mathrm{Cl}^{-}$.

As is found, the reactions for $\mathrm{Hg}^{0}$ emission are as follows: the main pathway is through mercuric-sulfite complexes [11, 13]:

$$
\begin{gathered}
\mathrm{Hg}^{2+}+\mathrm{SO}_{3}{ }^{2-} \longleftrightarrow \mathrm{HgSO}_{3} \\
\mathrm{HgSO}_{3}+\mathrm{SO}_{3}{ }^{2-} \longleftrightarrow \mathrm{Hg}\left(\mathrm{SO}_{3}{ }^{2-}\right)_{2} \\
\mathrm{HgSO}_{3}+\mathrm{H}_{2} \mathrm{O} \longrightarrow \mathrm{Hg}^{0} \uparrow+\mathrm{SO}_{4}{ }^{2-}+2 \mathrm{H}^{+} \\
\mathrm{Hg}\left(\mathrm{SO}_{3}{ }^{2-}\right)_{2}+\mathrm{H}_{2} \mathrm{O} \longrightarrow \mathrm{Hg}^{0} \uparrow+2 \mathrm{SO}_{4}{ }^{2-}+2 \mathrm{H}^{+}
\end{gathered}
$$

New mercuric-sulfite-chloride complexes $\mathrm{ClHgSO}_{3}{ }^{-}$and $\mathrm{Cl}_{2} \mathrm{HgSO}_{3}{ }^{2-}$ are formed through the following reactions when the chloride is added into the simulated desulfurization solutions:

$$
\begin{gathered}
\mathrm{HgSO}_{3}+\mathrm{Cl}^{-} \longleftrightarrow \mathrm{ClHgSO}_{3}{ }^{-} \\
\mathrm{ClHgSO}_{3}{ }^{-}+\mathrm{Cl}^{-} \longleftrightarrow \mathrm{Cl}_{2} \mathrm{HgSO}_{3}{ }^{2-}
\end{gathered}
$$

$\mathrm{ClHgSO}_{3}{ }^{-}$can decompose to $\mathrm{Hg}^{0}$ through the reaction (10). But the decomposition rate of $\mathrm{ClHgSO}_{3}{ }^{-}$is much slower than $\mathrm{HgSO}_{3}$ or $\mathrm{Hg}\left(\mathrm{SO}_{3}{ }^{2-}\right)_{2}$ (reactions (6) and (7)). In addition, $\mathrm{Cl}_{2} \mathrm{HgSO}_{3}{ }^{2-}$ is formed reversibly at higher chloride concentration, which does not decompose to $\mathrm{Hg}^{0}[12,16]$ :

$$
\mathrm{ClHgSO}_{3}{ }^{-}+\mathrm{H}_{2} \mathrm{O} \longleftrightarrow \mathrm{Hg}^{0} \uparrow+\mathrm{SO}_{4}{ }^{2-}+\mathrm{Cl}^{-}+2 \mathrm{H}^{+}
$$

From Figure 5(b), it can be seen that the $\mathrm{Cl}^{-}$seems to have a slight effect on the mercury partitioning in the byproducts. The proportion of mercury retained in the solid decreases from $76.85 \%$ to $70.31 \%$ when the $\mathrm{Cl}^{-}$concentration in the slurry increases from $0 \mathrm{ppm}$ to $5000 \mathrm{ppm}$.

\section{Conclusions}

An evaluation of the influence of the operating conditions, which included the $\mathrm{pH}$, temperature, $\mathrm{Cl}^{-}$concentrations, and oxygen concentrations, on $\mathrm{Hg}^{0}$ reemission from wet flue gas desulfurization slurry was carried out. The experimental results indicated that the $\mathrm{Hg}^{0}$ reemission rate from WFGD slurry increased as the operational temperatures and $\mathrm{pH}$ values increased. However, the $\mathrm{Hg}^{0}$ reemission rates decreased as the $\mathrm{O}_{2}$ concentration of flue gas and $\mathrm{Cl}^{-}$concentration of WFGD slurry increased. So the $\mathrm{Hg}^{0}$ reemission from WFGD system can be reduced or slowed by decreasing the temperature and $\mathrm{pH}$ or by using forced oxidation. The 
results of mercury partitioning behavior in the solid and liquid byproducts show that mercury retention in the solid fraction increased with the concentrations of $\mathrm{O}_{2}$ in flue gas decreasing and slightly decreased in mercury retention in the solid fraction with the temperature and $\mathrm{Cl}^{-}$concentration in the slurry rising. And there is no evident relation between mercury retention in the solid byproducts and the $\mathrm{pH}$. The present findings could be valuable for industrial application of characterizing and optimizing mercury control in wet FGD systems.

\section{Conflict of Interests}

The authors declare that there is no conflict of interests regarding the publication of this paper.

\section{Acknowledgments}

This work was financially supported by the National Natural Science Foundation of China (51076045), Hebei Provincial Natural Science Foundation of China (E2012502043), and Fundamental Research Funds for the Central Universities.

\section{References}

[1] R. K. Srivastava, N. Hutson, B. Martin, F. Princiotta, and J. Staudt, "Control of mercury emissions from coal-fired electric utility boilers," Environmental Science and Technology, vol. 40, no. 5, pp. 1385-1393, 2006.

[2] J. H. Pavlish, E. A. Sondreal, M. D. Mann et al., "Status review of mercury control options for coal-fired power plants," Fuel Processing Technology, vol. 82, no. 2-3, pp. 89-165, 2003.

[3] R. Ochoa-Gonzalez, P. Córdoba, M. Diaz-Somoano et al., "Differential partitioning and speciation of $\mathrm{Hg}$ in wet FGD facilities of two Spanish PCC power plants," Chemosphere, vol. 85, no. 4, pp. 565-570, 2011.

[4] R. Ochoa-Gonzalez, M. Diaz-Somoano, M. R. MartinezTarazona et al., "The capture of oxidized mercury from simulated desulphurization aqueous solutions," Journal of Environmental Management, vol. 120, pp. 55-60, 2013.

[5] J. Wang, W. Wang, W. Xu, X. Wang, and S. Zhao, "Mercury removals by existing pollutants control devices of four coal-fired power plants in China," Journal of Environmental Sciences, vol. 23, no. 11, pp. 1839-1844, 2011.

[6] Y. Wang, Y. Liu, Z. Wu, J. Mo, and B. Cheng, "Experimental study on the absorption behaviors of gas phase bivalent mercury in Ca-based wet flue gas desulfurization slurry system," Journal of Hazardous Materials, vol. 183, no. 1-3, pp. 902-907, 2010.

[7] A. Stergaršek, M. Horvat, J. Kotnik et al., "The role of flue gas desulphurisation in mercury speciation and distribution in a lignite burning power plant," Fuel, vol. 87, no. 17-18, pp. 35043512, 2008.

[8] T. Tang, J. Xu, R. Lu, J. Wo, and X. Xu, "Enhanced $\mathrm{Hg}^{2+}$ removal and $\mathrm{Hg}^{0}$ re-emission control from wet fuel gas desulfurization liquors with additives," Fuel, vol. 89, no. 12, pp. 3613-3617, 2010.

[9] N. Omine, C. E. Romero, H. Kikkawa, S. Wu, and S. Eswaran, "Study of elemental mercury re-emission in a simulated wet scrubber," Fuel, vol. 91, no. 1, pp. 93-101, 2012.

[10] J. Wo, M. Zhang, X. Cheng, X. Zhong, J. Xu, and X. Xu, " $\mathrm{Hg}^{2+}$ reduction and re-emission from simulated wet flue gas desulfurization liquors," Journal of Hazardous Materials, vol. 172, no. 2-3, pp. 1106-1110, 2009.

[11] J. C. Chang and S. B. Ghorishi, "Simulation and evaluation of elemental mercury concentration increase in flue gas across a wet scrubber," Environmental Science \& Technology, vol. 37, no. 24, pp. 5763-5766, 2003.

[12] Y. Liu, Y. Wang, Z. Wu, S. Zhou, and H. Wang, "A mechanism study of chloride and sulfate effects on $\mathrm{Hg}^{2+}$ reduction in sulfite solution," Fuel, vol. 90, no. 7, pp. 2501-2507, 2011.

[13] L. van Loon, E. Mader, and S. L. Scott, "Reduction of the aqueous mercuric ion by sulfite: $\mathrm{UV}$ spectrum of $\mathrm{HgSO}_{3}$ and its intramolecular redox reaction," Journal of Physical Chemistry A, vol. 104, no. 8, pp. 1621-1626, 2000.

[14] R. Ochoa-gonzalez, M. Diaz-somoano, M. R. Martineztarazona et al., "Control of $\mathrm{Hg}^{0}$ re-emission from gypsum slurries by means of additives in typical wet scrubber conditions," Fuel, vol. 105, pp. 112-118, 2013.

[15] C. L. Wu, Y. Cao, C. C. He, Z.-B. Dong, and W.-P. Pan, "Study of elemental mercury re-emission through a lab-scale simulated scrubber," Fuel, vol. 89, no. 8, pp. 2072-2080, 2010.

[16] D. W. Deberry, G. M. Blythe, S. Pletcher et al., Bench-Scale Kinetics Study of Mercury Reactions in FGD Liquors, Air and Waste Management Association, Baltimore, Md, USA, 2006. 

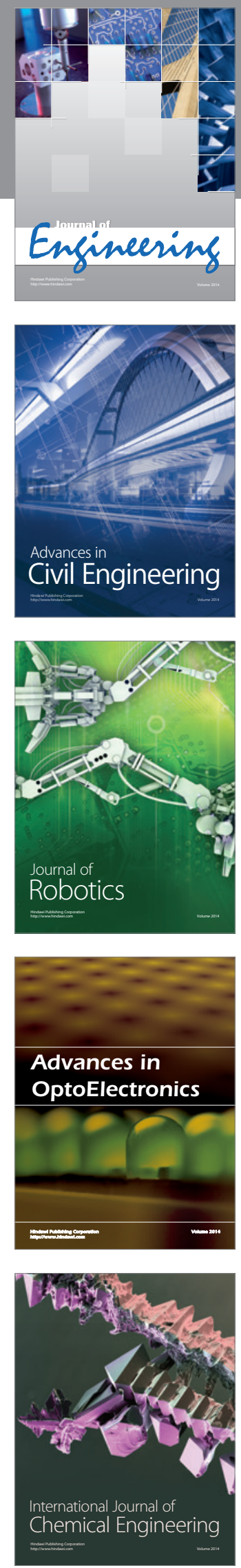

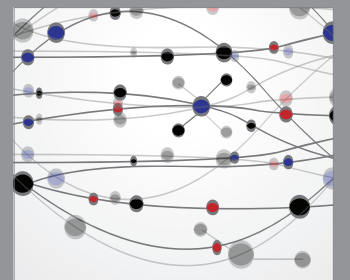

The Scientific World Journal
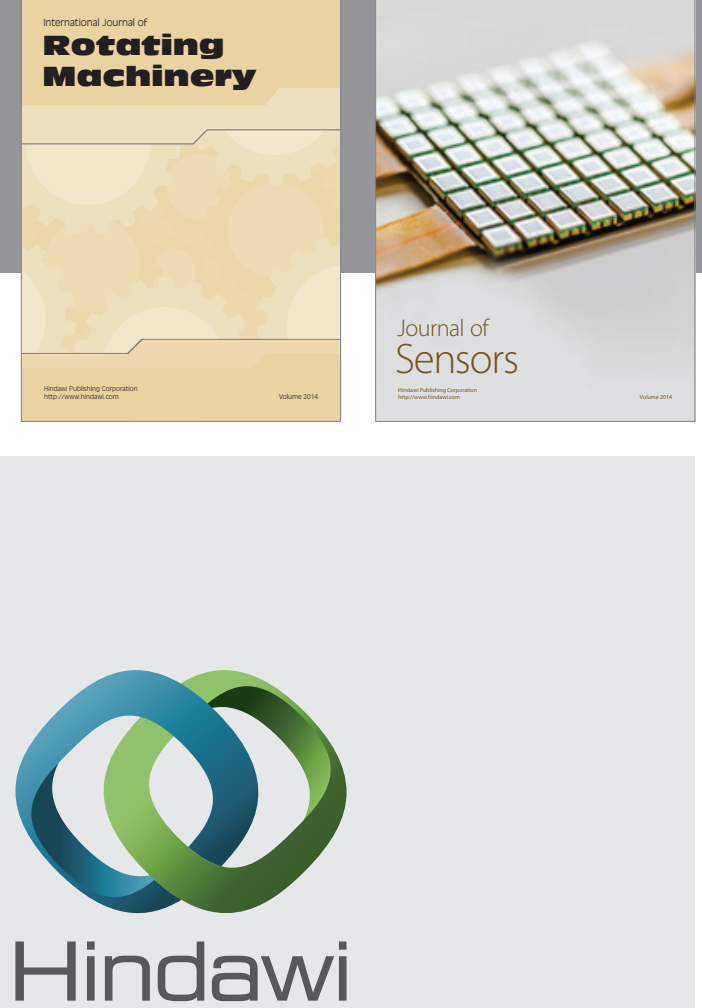

Submit your manuscripts at http://www.hindawi.com
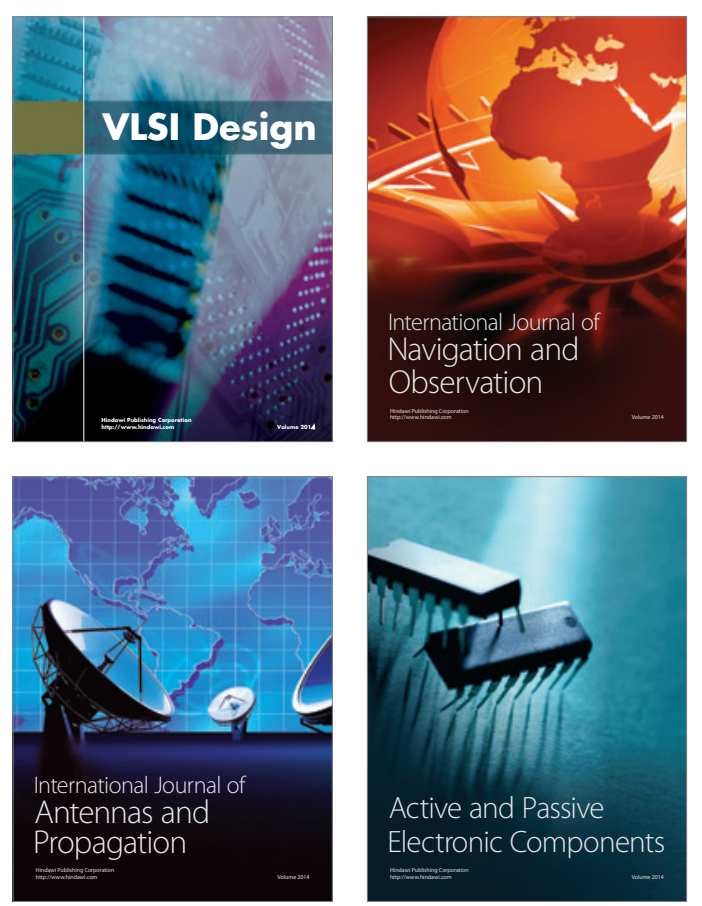
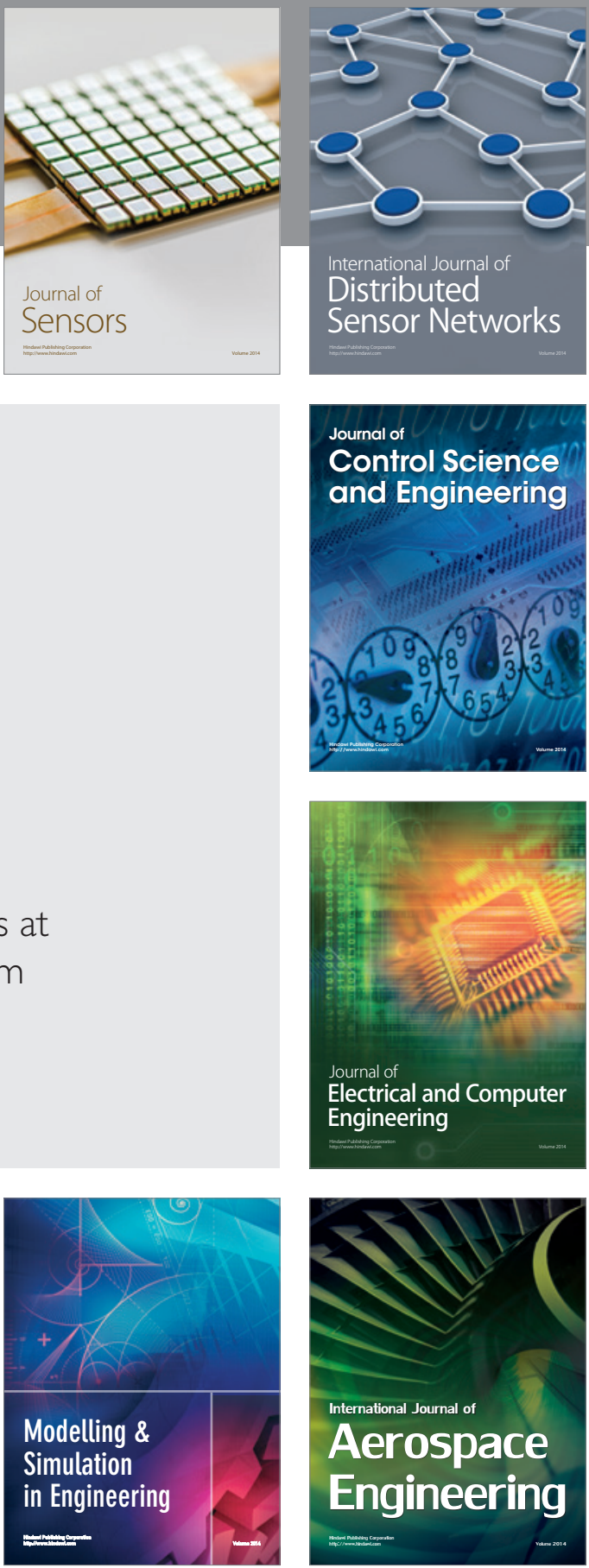

Journal of

Control Science

and Engineering
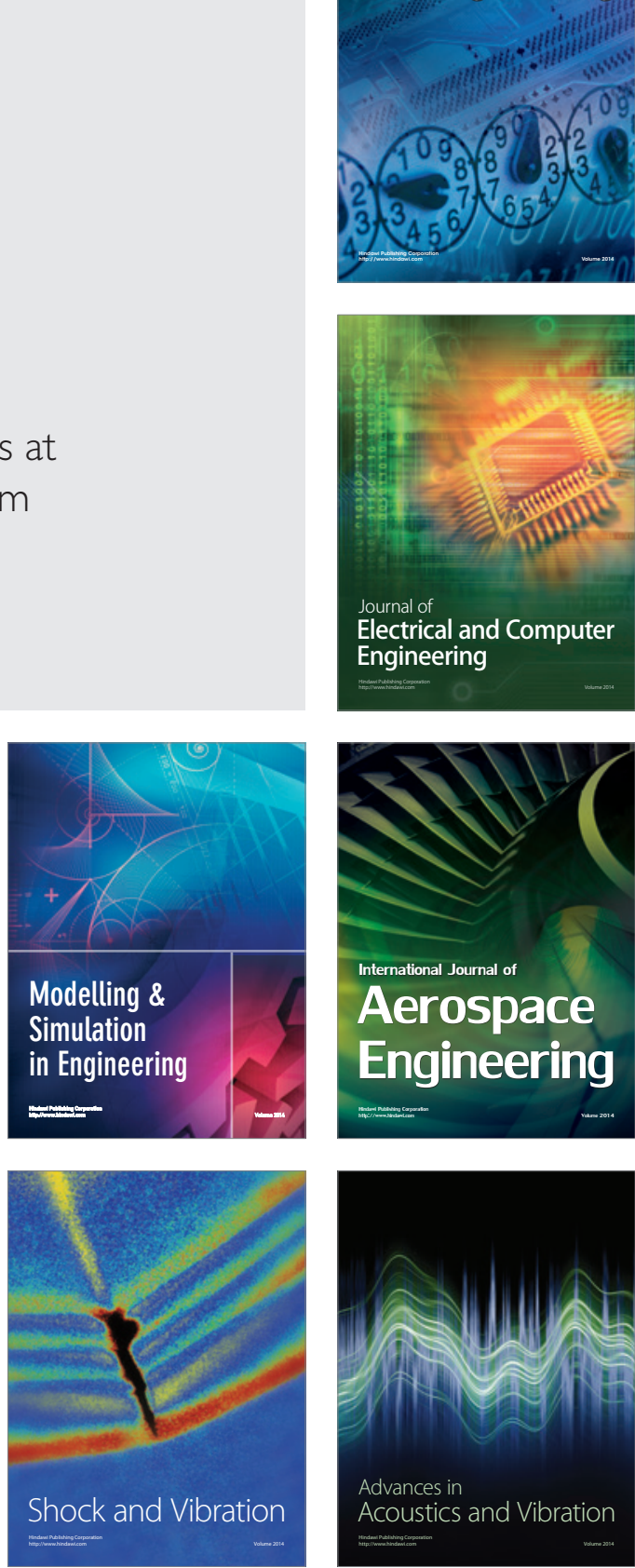